DOI: 10.1002/ ((please add manuscript number))

Article type: Full Paper

\title{
Light-Induced Degradation of Perovskite Solar Cells: The Influence of 4-tert-butyl pyridine and Gold
}

João P. Bastos, * Ulrich W. Paetzold, Robert Gehlhaar, Weiming Qiu, David Cheyns, Supriya Surana, Valentina Spampinato, Tom Aernouts and Jef Poortmans

J. P. B., Dr. U.W.P., W. Q., Dr. R. G., Dr. W.Q., Dr. D. C., S.S., Dr. V. S., Dr. T. A., Prof. J. P.

Imec - part of Solliance, Kapeldreef 75, 3001 Heverlee, Belgium

E-mail: joao.bastos@imec.be

J. P. B., Prof. J. P.

Department Electrical Engineering, Katholieke Universiteit Leuven, Kasteelpark Arenberg 10, B-3001, Leuven, Belgium

S.S.

Department Physics, Katholieke Universiteit Leuven, Celestijnenlaan 200d, B-3001, Leuven, Belgium

Dr. U.W.P.

Institute of Microstructure Technology, Karlsruhe Institute of Technology, Hermann-von-

Helmholtz-Platz 1, 76344 Eggenstein-Leopoldshafen, Karlsruhe, Germany

Prof. J. P.

Hasselt University, Institute for Materials Research \& IMEC-associated lab IMOMEC,

Wetenschapspark 1, B-3590 Diepenbeek, Belgium

Keywords: perovskite solar cells, stability, light

Stability is one of the key challenges for industrial scale commercialization of perovskite solar cells. In this work, a degradation mechanism that depends on materials and bias conditions of the device during light-soaking is proposed. The observed degradation is linked to the additive 4-tert-butyl pyridine (tBP), crucial to the hole transport layer of most perovskite solar cells, and gold. This conclusion is reached through the statistical analysis of multiple compositional profiles of light-soaked and non-light soaked devices and by selective replacement of material layers of the device. Moreover, the rate of the light-induced degradation is enhanced by operation at forward bias, which is required for power generation. Thus, this work stresses the need for the development of transport layers that do not require tBP, and to replace gold to produce high performing devices that are also stable under operating conditions. 


\section{Introduction}

The power conversion efficiency (PCE) of perovskite solar cells has quickly risen in the last years, with the highest certified value reaching that of the commercial thin-film solar cell technologies like CdTe or CIGS. ${ }^{[1]}$ This increase in efficiency is an indicator of the enormous potential of perovskite photovoltaics to become yet another commerical technology to harvest solar energy. The increase of PCE in perovskite solar cells has been mostly realized with the $n-i-p$ architecture,${ }^{[2-7]}$ meaning that the perovskite is sandwiched between an electron tranport layer, on the light incident front side, and a hole transport layer on the back side with the metallic contact. This type of perovskite solar cells architecture shows good potential in terms of efficiency, however, the long term stability still has to be proven for perovskite solar cells to achieve commercial viability.

Solar cells deployed outdoors are exposed to stresses like high temperatures, temperature fluctuations, rain, humidity and light cycles. While the effects of humidity and rain can be mitigated by packaging, applied even in Si modules to protect the air sensitive cabling, the solar cell has to be able to withstand the other stresses. Of highest importance is light stability, due to the inherent application of these devices. Therefore, studies about the intrinsic light stability of perovskite devices are essential. The intrinsic stability can be studied by performing long-term testing in an inert atmosphere like $\mathrm{N}_{2}$ or Argon, or by sufficiently packaging the devices.

There exists already a considerable amount of research on the intrinsic light stability of perovskite solar cells and different suggestions about the degradation sources. Initial reports suggested that light induced-heating was the source of irreversible degradation ${ }^{[8]}$ and that light-induced polarons caused reversible degradation. ${ }^{[9,10]}$ For the particular case of devices with the n-i-p architecture, there are reports proposing different causes for PCE reduction: reaction between titanium dioxide $\left(\mathrm{TiO}_{2}\right)$ and perovskite, ${ }^{[11-15]}$ movement of ions in the perovskite, ${ }^{[16-18]}$ hole transport layer induced degradation of the perovskite ${ }^{[7,15,19]}$ and gold $(\mathrm{Au})$ diffusion. ${ }^{[18,20]}$

In this paper, we propose a degradation mechanism that depends on the materials and bias conditions of the device during light-soaking. We study the intrinsic light stability of archetypal n-i-p devices: Indium Tin Oxide (ITO) / $\mathrm{TiO}_{2} /$ methyl ammonium lead iodide $\left(\mathrm{CH}_{3} \mathrm{NH}_{3} \mathrm{PbI}_{3}\right) / \mathrm{N}^{2}, \mathrm{~N}^{2}, \mathrm{~N}^{2}, \mathrm{~N}^{2^{\prime}}, \mathrm{N}^{7}, \mathrm{~N}^{7}, \mathrm{~N}^{7^{\prime}}, \mathrm{N}^{7^{\prime}}$ - octakis (4-methoxyphenyl) - 9, 9' - spirobi [9Hfluorene] - 2,2',7,7' - tetramine (spiro-MeOTAD) / $\mathrm{Au}$, and find that an additive of spiroMeOTAD, 4-tert-butyl pyridine (tBP) and Au are the source of degradation. We come to this 
conclusion through statistical analysis of multiple compositional profiles of devices that were either light-soaked or stored in the dark, variation of the composition of spiro-MeOTAD and factoring of the stresses the devices are subjected during light-soaking. Moreover, this degradation is associated to a reduction of short-circuit density, that is caused by the reduction of the carrier lifetime in $\mathrm{CH}_{3} \mathrm{NH}_{3} \mathrm{PbI}_{3}$.

\section{Results and Discussion}

\subsection{Light Soaking: Fast and Slow Degradation}

Recent publications indicate that light-induced degradation of perovskite solar cells depends on factors like temperature, ${ }^{[8,21]}$ bias conditions ${ }^{[16,17,21]}$ and the layer stack. ${ }^{[11-}$ 13,15,18,20,22] In this work, we focus on the intrinsic light stability of the material stack at bias conditions that replicate outdoor deployment. For this purpose, the devices are light soaked under 1 sun, at a forward bias (maximum power point voltage or open-circuit voltage) in $\mathrm{N}_{2}$ (ISOS L-1). ${ }^{[23]}$ To exclude additional degradation induced by heating, such as $\mathrm{Au}$ migration $^{[20]}$ and crystallization of the hole transport layer, spiro-MeOTAD (which has a glass transition temperature of $75{ }^{\circ} \mathrm{C}$ when 4-tert-Butylpyridine (tBP) is added), ${ }^{[24]}$ we actively keep the devices to $45^{\circ} \mathrm{C} \pm 5{ }^{\circ} \mathrm{C}$ by water cooling the test chamber.

Devices that are light-soaked while forward biased, either at maximum power point (MPP, adjusted every 30 seconds with a perturb and observe algorithm), or at open-circuit (measured by current density-voltage ( $J-V)$ sweeps every 20 minutes from reverse to forward), present a 'fast' initial degradation that is followed by 'slow' degradation (Figure 1a). The power conversion efficiency (PCE) curves of the devices are fit with exponential functions in the 'slow' and 'fast' degradation regions (Table 1). The time constants of all the 'slow' degradation, $t_{s}$, are of the order of thousands of hours, and the time constants for all the 'fast' degradation, $t_{f}$, are in the order of tens of hours, indicating the existence of two distinct degradation paths. The 'fast' degradation is of special concern because it causes a large loss in PCE in 100 hours and is the focus of this work. 
a)

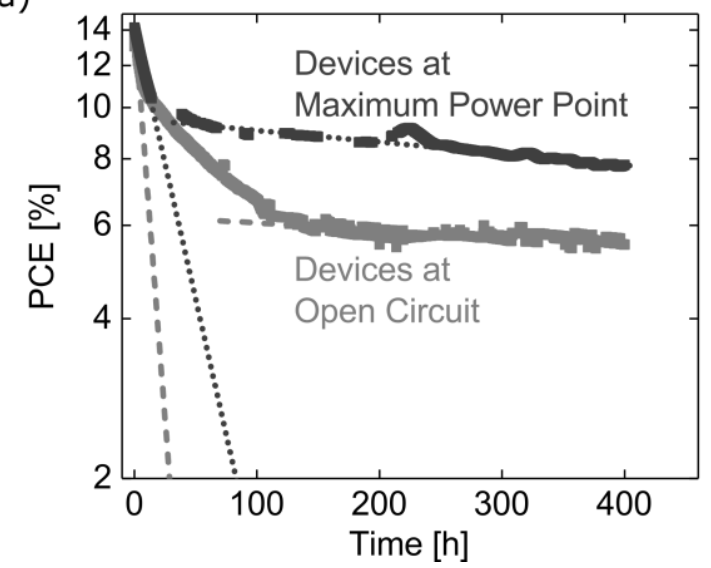

b)

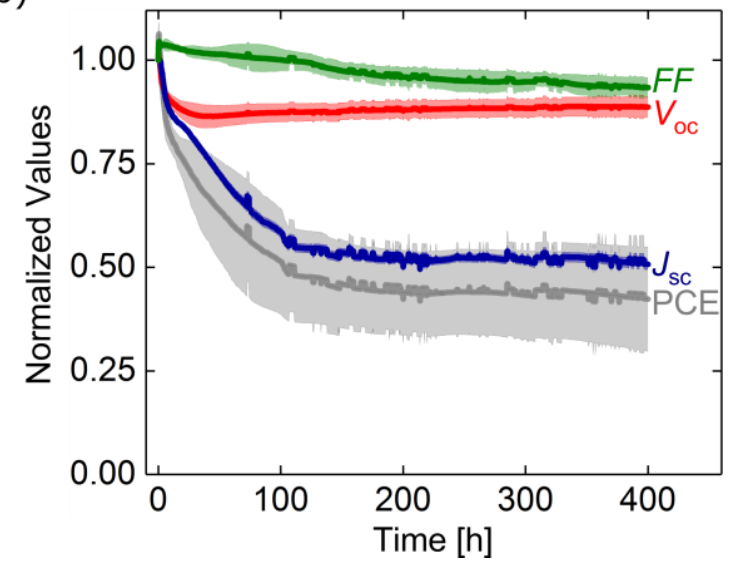

Figure 1 - a) Evolution of the PCE of light-soaked devices (under simulated AM1.5G 1 sun) at forward bias: at open circuit (grey) and at maximum power point (dark grey). The corresponding exponential fits for the fast and slow degradation regions are shown in interrupted lines. b) Normalized performance parameters: power conversion efficiency (PCE, grey), short-circuit current density $\left(J_{\mathrm{sc}}\right.$, blue), open-circuit voltage $\left(V_{o c}\right.$, red $)$ and fill factor $(F F$, green).

Table 1. Exponential degradation parameters of devices under $100 \mathrm{~mW} \mathrm{~cm}{ }^{-2}$ illumination held at different bias conditions.

\begin{tabular}{lcccc}
\hline \multicolumn{1}{c}{ Bias Condition } & \multicolumn{2}{c}{ 'Fast' degradation } & \multicolumn{2}{c}{ 'Slow' degradation } \\
& $\begin{array}{c}\mathrm{PCE}_{\mathrm{f}} \\
{[\%]}\end{array}$ & $\begin{array}{c}\mathrm{t}_{\mathrm{f}} \\
{[\text { hours] }}\end{array}$ & $\begin{array}{c}\mathrm{PCE}_{\mathrm{s}} \\
{[\%]}\end{array}$ & $\begin{array}{c}\mathrm{t}_{\mathrm{s}} \\
{[\text { hours] }}\end{array}$ \\
\hline Maximum Power Point & 14.1 & 42 & 9.5 & 1961 \\
Open-Circuit & 14.6 & 15 & 6.3 & 4762 \\
\hline
\end{tabular}

The 'fast' degradation is associated to a $50 \%$ loss of short-circuit current density $\left(J_{\mathrm{sc}}\right)$, and $15 \%$ loss of both the open-circuit voltage $\left(V_{\mathrm{oc}}\right)$ and the fill factor $(F F)$ (Figure $1 \mathrm{~b}$ and Figure S1). Therefore, the focus of this paper is on the $J_{\mathrm{sc}}$ reduction. The $V_{\mathrm{oc}}$ and the $F F$ are not analyzed. Moreover, we note that all the device parameters here reported are the average of at least seven devices and error bar represents the standard deviation.

The $J_{\text {sc }}$ reduction is due to changes in either generation or recombination, and not due to the formation of extraction barriers, since the $F F$ is only mildly affect by prolonged light soaking. A better understanding of the effect of generation and recombination on $J_{\mathrm{sc}}$ is provided by the continuity equation for the $J_{\mathrm{sc}}$ in steady state. According to this equation, the magnitude of the current depends on the generation rate $(G)$ and recombination rate $(U)$ at any point in photo-active layer. Moreover, $U$ can be written as function of the excess of carriers $(\Delta n)$ and carrier lifetime $\left(\tau_{n}\right)$, resulting in the following expression for the electron current (the hole current can be expressed through a similar equation): 
$I_{n}(x)=q \int_{0}^{x}\left(G_{n}(x)-\frac{\Delta n(x)}{\tau_{n}}\right) d x$

Equation 1

As Equation 1 shows, the current of solar cells will decrease with a reduction of the generation rate, and/or of carrier lifetime. A reduction of the generation rate would mean that the absorptance of $\mathrm{CH}_{3} \mathrm{NH}_{3} \mathrm{PbI}_{3}$ decreases by prolonged illumination, and, hence, that light alone is sufficient to degrade $\mathrm{CH}_{3} \mathrm{NH}_{3} \mathrm{PbI}_{3}$. However, the absorptance of light-soaked devices is only slightly lower than dark-stored devices in the $600-800 \mathrm{~nm}$ range (Figure 2a). This small difference in absorptance, in a limited part of the $\mathrm{CH}_{3} \mathrm{NH}_{3} \mathrm{PbI}_{3}$ absorbing range (300$800 \mathrm{~nm}$ ), cannot explain the large reduction of $J_{\text {sc. }}$. Moreover, the X-ray diffraction (XRD) of $\mathrm{CH}_{3} \mathrm{NH}_{3} \mathrm{PbI}_{3}$ films from light-soaked devices present no signals of degradation products, like $\mathrm{PbI}_{2}$ (Figure 2b), confirming that light-soaking does not cause significant changes to the $\mathrm{CH}_{3} \mathrm{NH}_{3} \mathrm{PbI}_{3}$. Since the generation rate is not changed, and consequently the number of generated charges, the reduction of the $J_{\mathrm{sc}}$ should be caused by the reduction of the carrier lifetime. The increase of the ideality factor of the devices during light-soaking indeed indicates that recombination increases over time, hence, the lifetime of the carriers is reduced (Figure S1). 
a)

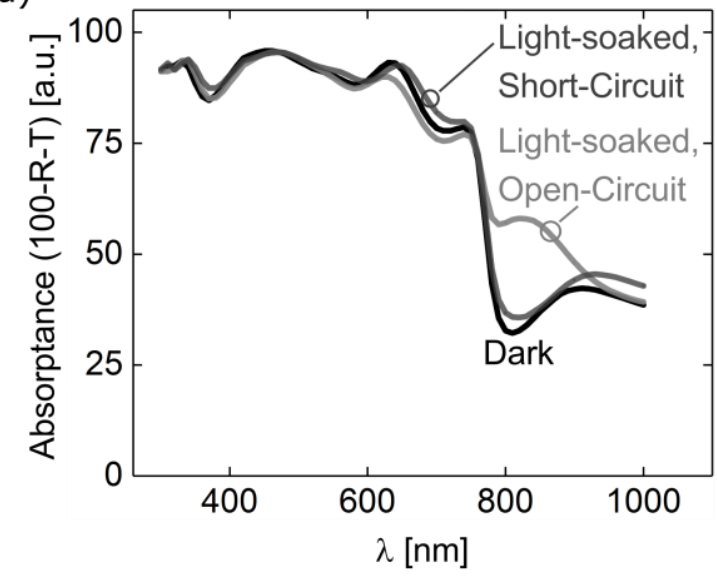

C)

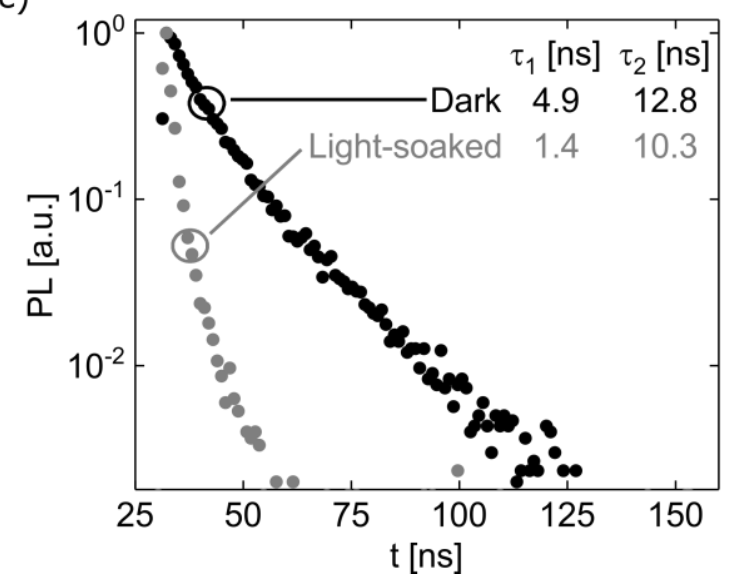

b)

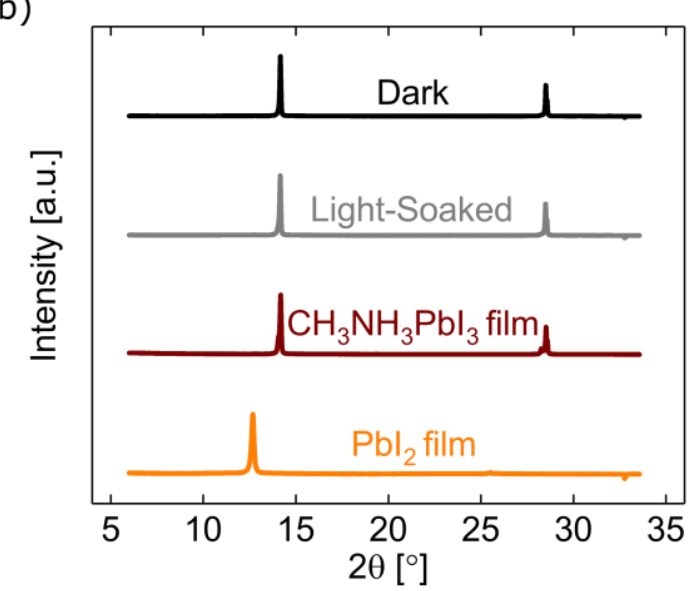

d)

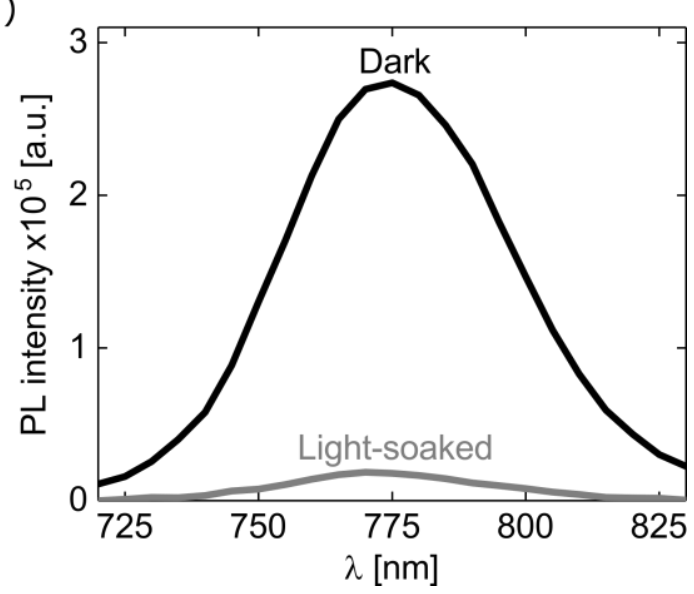

Figure 2 - Characterization of light-soaked devices and devices stored in the dark: a) Absorptance of devices stored in the dark and under illumination after 100 hours; b) XRD measurements of perovskite films from devices that were light-soaked or stored in the dark for 100 hours, compared to a pristine $\mathrm{PbI}_{2}$ layer; c) Transient $\mathrm{PL}$ of $\mathrm{CH}_{3} \mathrm{NH}_{3} \mathrm{PbI}_{3}$ films from devices that were light-soaked or stored in the dark for 100 hours; d) Steady-state $\mathrm{PL}$ emission of $\mathrm{CH}_{3} \mathrm{NH}_{3} \mathrm{PbI}_{3}$ films from devices that were light-soaked or stored in the dark for 100 hours. Both absorptance and XRD show no evidences of degradation of $\mathrm{CH}_{3} \mathrm{NH}_{3} \mathrm{PbI}_{3}$ upon prolonged light-soaking, but PL measurements show that the lifetime of the carrier is reduced by the same proloned light-soaking.

To confirm that the reduction of the $J_{\mathrm{sc}}$ is caused by the reduction of the carrier lifetime, we compare the photoluminescence (PL) properties of ITO / $\mathrm{TiO}_{2} / \mathrm{CH}_{3} \mathrm{NH}_{3} \mathrm{PbI}_{3}$ layer stacks from light-soaked devices and from devices stored in the dark (details about the protocol utilized to expose the $\mathrm{CH}_{3} \mathrm{NH}_{3} \mathrm{PbI}_{3}$ are presented in Figure $\mathrm{S} 2$ and in the experimental section). The layer stacks from light-soaked devices present a shorter carrier lifetime and a lower intensity PL emission than films from devices stored in the dark (Figure 2c, 2d and S3). These PL measurements confirm that the reduction of the $J_{\mathrm{sc}}$ upon lightsoaking is caused by a decrease in carrier lifetime, which is in line with other reports for similar devices in similar stress conditions. ${ }^{[18,25]}$ Thus, identifying the material, layer, interface or additive that is causing this fast degradation is of key importance. 
2.2. Locating the Origin of Light Induced Degradation in the Device

Time-of-flight secondary ion mass spectrometry (ToF-SIMS) measurements as a function of depth provide information about the composition profile of a sample. This technique is here applied to study the effect of light-soaking in the devices. We analyze four devices light-soaked for 100 hours and four devices stored in the dark for the same period. We note that we remove the $\mathrm{Au}$ and the top part of spiro-MeOTAD of the devices to have a better resolution of the remaining layers (for more details see the experimental section).

The compositional profiles of dark stored devices and light-soaked devices differ mostly on the distribution of the spiro-MeOTAD additives, namely $\mathrm{Li}\left(\mathrm{Li}^{+}\right)$and tBP $\left(\mathrm{C}_{9} \mathrm{H}_{13} \mathrm{~N}^{+}\right.$), from the spiro-MeOTAD / $\mathrm{CH}_{3} \mathrm{NH}_{3} \mathrm{PbI}_{3}$ interface to the $\mathrm{CH}_{3} \mathrm{NH}_{3} \mathrm{PbI}_{3}$ bulk (Figure 3a). Moreover, tBP-related ions, like $\mathrm{C}_{8} \mathrm{H}_{10} \mathrm{~N}^{+}$, a tBP fragment without a methyl group, $\mathrm{C}_{9} \mathrm{H}_{14} \mathrm{~N}^{+}$, protonated tBP, and $\mathrm{C}_{9} \mathrm{H}_{20} \mathrm{~N}^{+}$, a rearranged molecule of tBP (Figure S4) show a marked increase from the spiro-MeOTAD / $\mathrm{CH}_{3} \mathrm{NH}_{3} \mathrm{PbI}_{3}$ interface to the $\mathrm{CH}_{3} \mathrm{NH}_{3} \mathrm{PbI}_{3}$ bulk (Figure S5). Also, Au is not detected in any of the devices, which we attribute to the low experimental temperature of $45^{\circ} \mathrm{C}$, chosen to prevent Au diffusion, ${ }^{[20]}$ and the removal of the Au prior to the ToF-SIMS measurement. Thus, these measurements indicate that light-soaking changes the distribution of the tBP and Li in the devices. However, this observation still requires statistical validation to ensure that the differences are meaningful. 

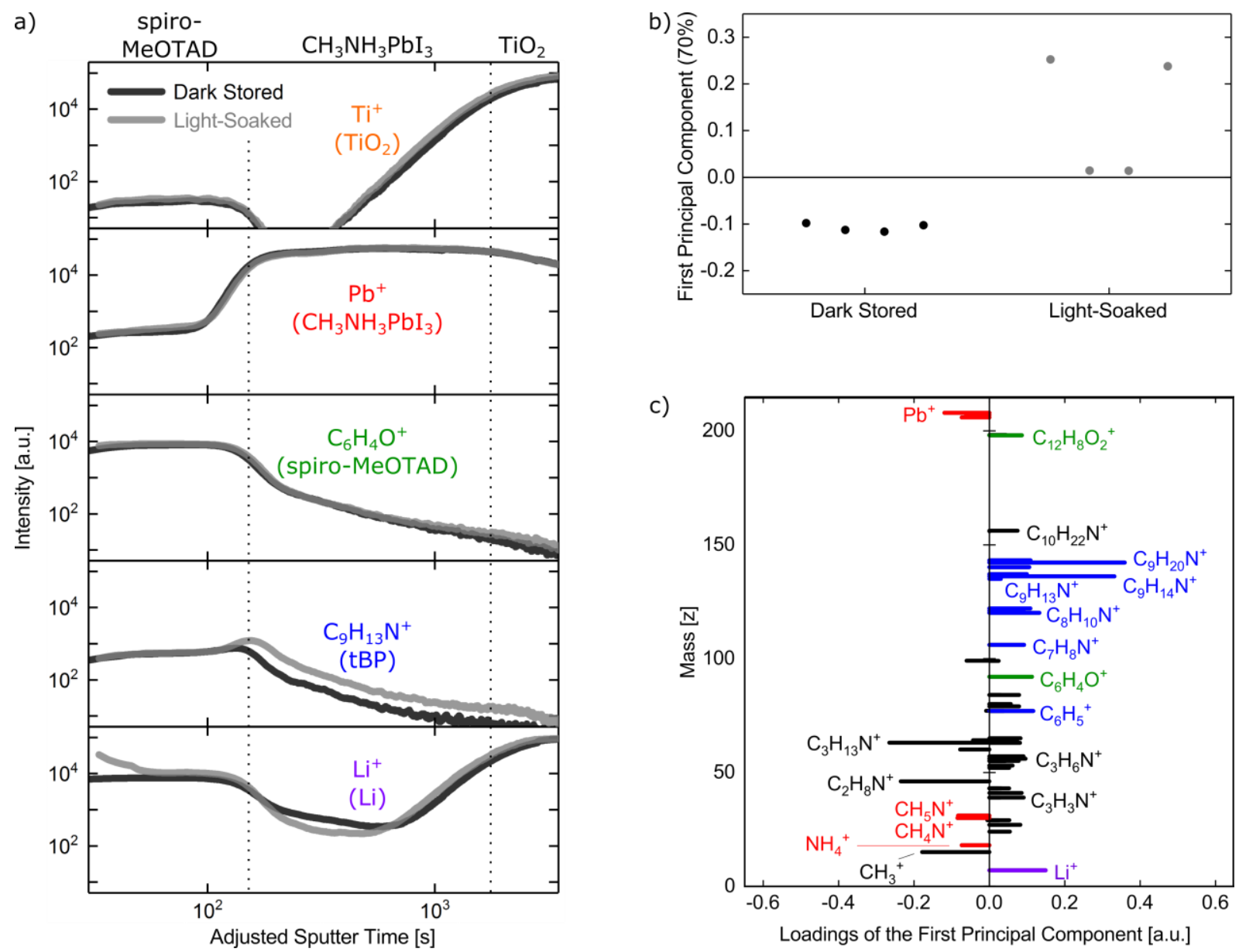

Figure 3 - Analysis of the compositional profiles and PCA demonstrate the influence of light-soaking in the composition of the devices: a) representative compositional profiles (normalized to the $\mathrm{Pb}^{+}$ion) of devices that were kept in the dark (black) or were light-soaked for 100 hours (grey) show changes of the tBP and Li profiles after light-soaking. For all the composition profiles see Figure S4; b) the first principal component scores of the four devices kept in the dark and of four light-soaked devices have different signs, demonstrating differences in the compositions; c) the loadings of the first principal component demonstrate that light-soaked devices present higher contents of tBP-related ions (blue). Ions related to spiro-MeOTAD (green), $\mathrm{CH}_{3} \mathrm{NH}_{3} \mathrm{PbI}_{3}$ (red), and LiTFSI (purple) are also highlighted.

To guarantee that any difference between dark stored and light-soaked devices are significant, we perform a statistical analysis considering all the compositional profiles. We use Principal Components Analysis (PCA), a multivariate analysis techniques utilized in the identification of the mass peaks responsible for differences between samples. ${ }^{[26,27]}$ This analysis is an orthogonal linear transformation that defines a new coordinate system that maximizes variance (the square of the standard deviation), so that the variance along the coordinate decreases with increasing coordinate order. Therefore, the first coordinate, also called first principal component, explains the largest portion of the variance in the dataset, and expresses the most important differences between samples.

The PCA is performed with the compositional profiles of the eight samples from the spiro-MeOTAD / $\mathrm{CH}_{3} \mathrm{NH}_{3} \mathrm{PbI}_{3}$ interface to the $\mathrm{CH}_{3} \mathrm{NH}_{3} \mathrm{PbI}_{3}$ bulk, where most of the 
differences were detected. The first principal component of the PCA explains $70 \%$ of the variance and clearly distinguishes the devices stored in the dark (negative scores in Figure 3b) from the light-soaked devices (positive scores in Figure 3b). This difference in scores means that light-soaking causes measurable changes in the $\mathrm{CH}_{3} \mathrm{NH}_{3} \mathrm{PbI}_{3}$ layer, in agreement with the PL measurements (Figure 2). Moreover, the loading plot of the first principal component (the values by which the original intensity of each mass is multiplied in this linear transformation) confirms that tBP-related ions are the largest contributors for the positive scores of the lightsoaked samples (the loadings of the tBP-related ions are displayed in blue in Figure $3 \mathrm{c}$ ). Interestingly, the tBP molecular ion $\left(\mathrm{C}_{9} \mathrm{H}_{13} \mathrm{~N}^{+}\right)$has a low loading value compared with tBPrelated ions like $\mathrm{C}_{8} \mathrm{H}_{10} \mathrm{~N}^{+}, \mathrm{C}_{9} \mathrm{H}_{14} \mathrm{~N}^{+}$, and $\mathrm{C}_{9} \mathrm{H}_{20} \mathrm{~N}^{+}$, which have the highest loadings. This difference in the loading values of the tBP and tBP-related ions under the same beam conditions strongly indicates that $\mathrm{tBP}$ is altered by light-soaking. The tBP might degrade by itself, or react with $\mathrm{CH}_{3} \mathrm{NH}_{3} \mathrm{PbI}_{3}{ }^{[28-31]}$ The reaction between $\mathrm{CH}_{3} \mathrm{NH}_{3} \mathrm{PbI}_{3}$ and tBP is suggested to result in a complex between $\mathrm{PbI}_{2}$ and $\mathrm{tBP} .{ }^{[32]}$ This reaction is not very extensive, ${ }^{[32]}$ which could explain both the absence measurable of degradation products in the XRD measurements (Figure 2b) and the slightly lower absorption of the light-soaked devices (Figure 2a). ${ }^{[32]}$ However, the exact reaction(s) leading to the increased signal of tBP-related ions are out of the scope of this work. Nevertheless, these findings plainly establish a correlation between the change in the distribution of tBP-related ions and the reduction of the $J_{\text {sc }}$ after light-soaking. Further investigations are required to verify the causality between these two observations.

To ensure that $\mathrm{tBP}$ is the cause of the reduction of the $J_{\mathrm{sc}}$, we compare the effects of light-soaking on devices with different spiro-MeOTAD formulations. The typical formulation of spiro-MeOTAD involves adding $17.5 \mu$ l solution of bis(trifluoromethane)sulfonimide lithium (LiTFSI) $(500 \mathrm{mg} / \mathrm{ml}$ in acetonitrile) and $28.5 \mu \mathrm{l}$ tBP to $80 \mathrm{mg}$ of spiro-MeOTAD per $\mathrm{ml}$ of chlorobenzene. Devices with only tBP added to spiro-MeOTAD have average PCE of $2 \%$ (Figure S6), and are therefore not tested. Devices with the typical spiro-MeOTAD formulation are light-soaked side-by-side with devices with only LiTFSI in spiro-MeTOAD and devices with neat spiro-MeOTAD. All the devices, independent of the spiro-MeOTAD formulation, present a small $\left(\sim 1 \mathrm{~mA} \mathrm{~cm}^{-2}\right)$ but very fast $J_{\mathrm{sc}}$ reduction in the initial 10 hours, as reported before and attributed to reversible cation movement. ${ }^{[17]}$ Thereafter, the devices with tBP and LiTFSI in spiro-MeOTAD present a continuous $J_{\text {sc }}$ reduction, while the devices fabricated with neat spiro-MeOTAD, or only with LiTFSI in spiro-MeOTAD, present no further $J_{\mathrm{sc}}$ losses (Figure 4). These results confirm that tBP causes the reduction of $J_{\text {sc. }}$. 
Moreover, these results demonstrate that neither $\mathrm{Li}$ or $\mathrm{Au}$ are the source of the degradation, because these elements are present in devices with minimal $J_{\text {sc }}$ losses. However, it is not clear whether tBP alone causes the reduction of $J_{\mathrm{sc}}$, or if other components are necessary to cause this reduction.

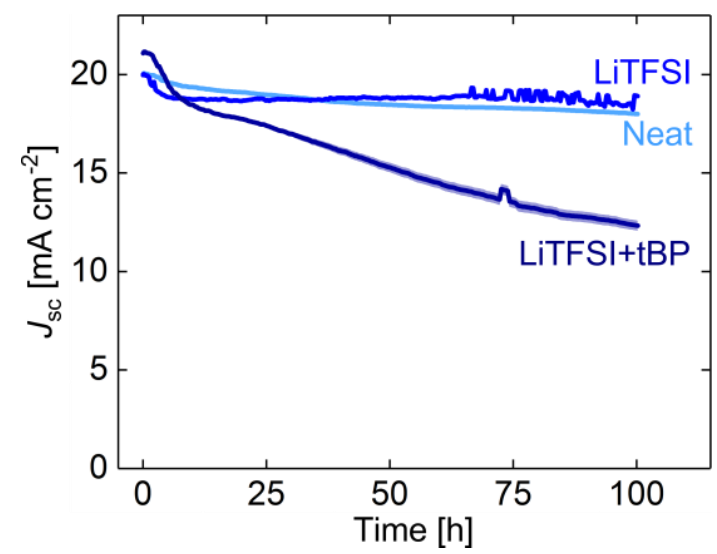

Figure 4 - Evolution of the short-circuit density current of devices: with different spiro-MeOTAD formulations. Only devices with tBP present the short-circuit density current reduction.

Additional experiments with representative layer stacks (LS) demonstrate that the $J_{\text {sc }}$ reduction requires both $\mathrm{tBP}$ and Au. Firstly, stacks with progressively less layers than the device, i.e., LS-1 - ITO / $\mathrm{TiO}_{2} / \mathrm{CH}_{3} \mathrm{NH}_{3} \mathrm{PbI}_{3} /$ spiro-MeOTAD, LS-2 - ITO / $\mathrm{TiO}_{2} /$ $\mathrm{CH}_{3} \mathrm{NH}_{3} \mathrm{PbI}_{3}$, and LS-3 - ITO / $\mathrm{TiO}_{2}$, are light soaked for 100 hours. Secondly, these stacks are completed with the necessary layers to transform them into devices. Finally, the devices are measured (see Figure 5a). The devices from LS-1 present a slightly lower $J_{\text {sc }}$, but still within error bar of the reference device, and devices from LS-2 and LS-3 have performances comparable with the reference devices completed at once (Figure 5b and Figure S7). These results demonstrate that $\mathrm{Au}$ is important for the reduction of the $J_{\mathrm{sc}}$, in agreement with previous reports. ${ }^{[15,33]}$ Possible reasons for the role of $\mathrm{Au}$ are: i) Au is known to complex with pyridines, ${ }^{[34,35]}$ and this complex could decrease the energy required for light-induced degradation of tBP. Light-activated degradation of tBP in the presence of Au could explain the increase of tBP-related ions in light-soaked devices (see Figure S5); ii) Au might act as a barrier for diffusion of tBP out of spiro-MeOTAD, since tBP is known to evaporate from uncapped spiro-MeOTAD over time. ${ }^{[24]}$ If the reduction of the $J_{\mathrm{sc}}$ is driven by the reaction of $\mathrm{CH}_{3} \mathrm{NH}_{3} \mathrm{PbI}_{3}$ with $\mathrm{tBP}$, the presence of the $\mathrm{Au}$ in devices should result in a faster reduction of the $J_{\mathrm{sc}}$ than in devices from LS-1. This mechanism could explain the slightly lower $J_{\mathrm{sc}}$ of the devices from LS-1 compared with devices LS-2 and LS-3. 
The devices from the LS-2 and LS-3 further prove that the $J_{\mathrm{sc}}$ reduction cannot be attributed to the degradation of $\mathrm{TiO}_{2}$ or $\mathrm{CH}_{3} \mathrm{NH}_{3} \mathrm{PbI}_{3}$ by light, because the light-soaking of these stacks causes no reduction of the $J_{\text {sc }}$ (Figure $5 b$ ), or any other device parameter (Figure S4). These observations agree with complimentary experiments that demonstrate that the replacement of the $\mathrm{TiO}_{2}$ by other electron transports layer systems $\left(\mathrm{TiO}_{2} / \mathrm{PCBM}\right.$ and PEIE/PCBM), or fabrication of $\mathrm{CH}_{3} \mathrm{NH}_{3} \mathrm{PbI}_{3}$ by another recipe, do not prevent the fast degradation under light soaking (Figure S8).

a)

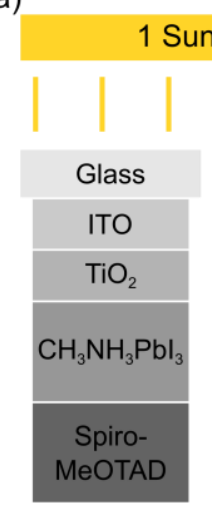

LS-1
Sun illumination, $100 \mathrm{~h}$

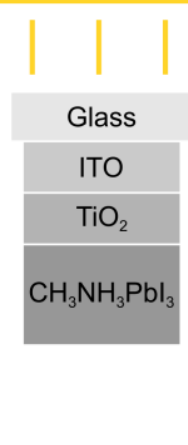

LS-2

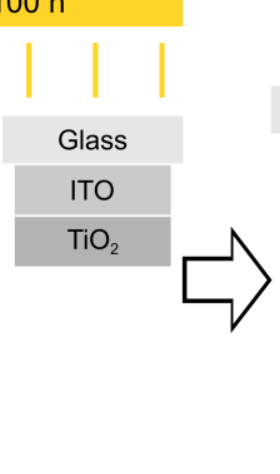

LS-3 b)

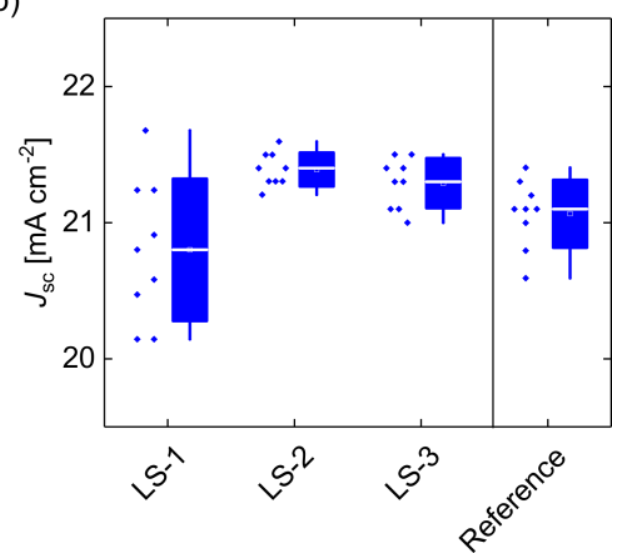

Figure 5 - a) Schematic of the partial stacks that were light soaked for $100 \mathrm{~h}$ before being completed; b) short-current density of nine devices completed from partial stacks compared with a device completed at once. Light-soaking of layer stacks has no significant impact on the $J_{\mathrm{sc}}$ of the final devices.

\subsection{Suggested Degradation Mechanism for the $J_{\mathrm{sc}}$ Reduction}

The physical mechanism responsible for the reduction of $J_{\mathrm{sc}}$ is investigated by factoring the different stresses present during light-soaking. First, the UV radiation from the lamp could trigger the degradation. However, the presence of a UV filter (400 nm cut off) does not prevent the $J_{\mathrm{sc}}$ reduction, demonstrating that the degradation is not due to UV radiation (Figure 6a). ${ }^{[21]}$

a)

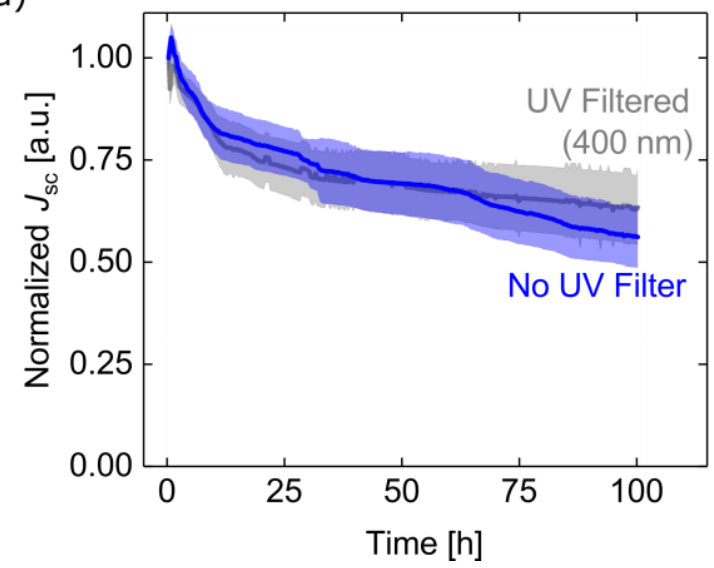

b)

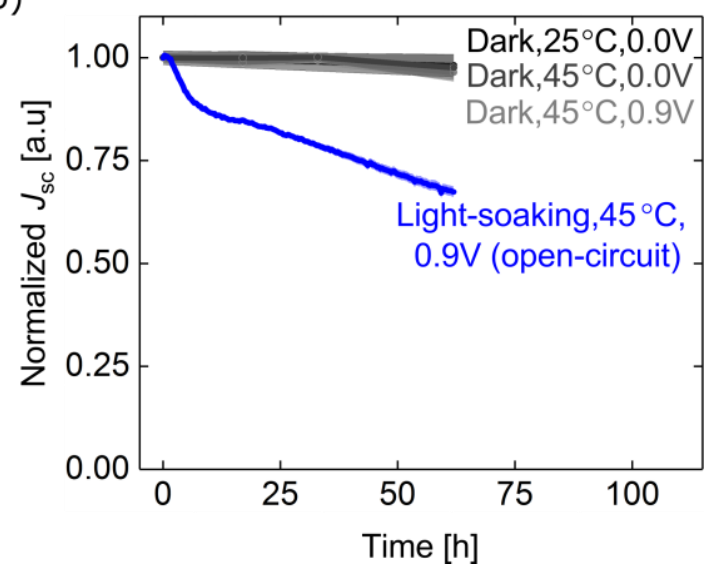


Figure 6 - a) Evolution of the normalized short-circuit current density under constant light soaking with UV filter or without, shows that UV light is not the source of degradation; b) Evolution of the normalized short-circuit current density of devices after 60 hours of stress at different temperatures $\left(25^{\circ} \mathrm{C}\right.$ and $\left.45^{\circ} \mathrm{C}\right)$, bias conditions $(0 \mathrm{~V}$ and $+0.9 \mathrm{~V})$ and illumination conditions (dark and light-soaked), show that the reduction of short-current density cannot be reproduced in the dark.

The other changes to the devices upon light-soaking are: i) temperature rise to $45^{\circ} \mathrm{C}$, ii) reduction of the internal field, because the devices are left at open circuit, or MPP. To decouple the effect of the temperature, of the internal field, and of illumination, we reproduce the temperature and internal field conditions in the dark for 62 hours. Devices are heated at $45{ }^{\circ} \mathrm{C}$ either at short-circuit or $0.9 \mathrm{~V}$ forward bias (open-circuit voltage upon illumination), to strongly reduce the internal field. Devices that are heated in the dark for 60 hours barely lose any $J_{\mathrm{sc}}$, just like control devices kept at $25{ }^{\circ} \mathrm{C}$ (Figure $6 \mathrm{~b}$ ). When the devices are forward biased and heated, a $J_{\mathrm{sc}}$ reduction is observed in the initial measurements, but after some minutes of light soaking at open-circuit, ${ }^{[36]}$ the $J_{\text {sc }}$ recovers to initial values (Figure S9). These results demonstrate that the reduction of the $J_{\mathrm{sc}}$ in light-soaked devices cannot be explained by the increase in temperature or reduction of the internal field in the device in the dark. Therefore, the diffusion of both neutral, or charged, species, present in the device from fabrication, can be excluded as the source of the $J_{\mathrm{sc}}$ reduction.

Since the observed $J_{\mathrm{sc}}$ reduction cannot be explained by diffusion of species already present in the device, we investigate light-activated mechanisms that could explain this reduction. To compare with the previous experiment, the temperature is fixed at $45{ }^{\circ} \mathrm{C}$ and the illumination power set to 1 sun, while the internal field of the devices is varied by leaving the devices either at open-circuit or short-circuit. We observe that the short-circuited devices have a smaller reduction of $J_{\mathrm{sc}}$ and that they even recover a substantial part of the $J_{\mathrm{sc}}$ when left at open-circuit (Figure 7a). This 'apparent' recovery could be explained by ionic screening disappearing as the drive for the movement of ions, the internal field, is reduced by illuminating devices at open-circuit. But more importantly, after two hours of 'recovery' the $J_{\mathrm{sc}}$ of short-circuited devices, is larger than the $J_{\mathrm{sc}}$ of devices at open-circuit after the first 100 hours, showing that the $J_{\text {sc }}$ reduction is limited if the internal field is not zero. These results are confirmed by a similar experiment, in which the devices are either left at opencircuit or shorted during 100 hours of light-soaking. Again, the devices that were shorted during light-soaking presented a much smaller reduction of $J_{\mathrm{sc}}$ than devices left at open-circuit (Figure 7b). Moreover, the devices held at short-circuit during light-soaking do not present an additional absorption peak that is present for devices light-soaked at open-circuit (Figure 2a), indicating less changes to the device. Thus, the internal field during light soaking influences 
the device degradation. This observation also agrees with the slower degradation kinetics of the devices at maximum power point compared with the devices at open-circuit (Table 1).

a)

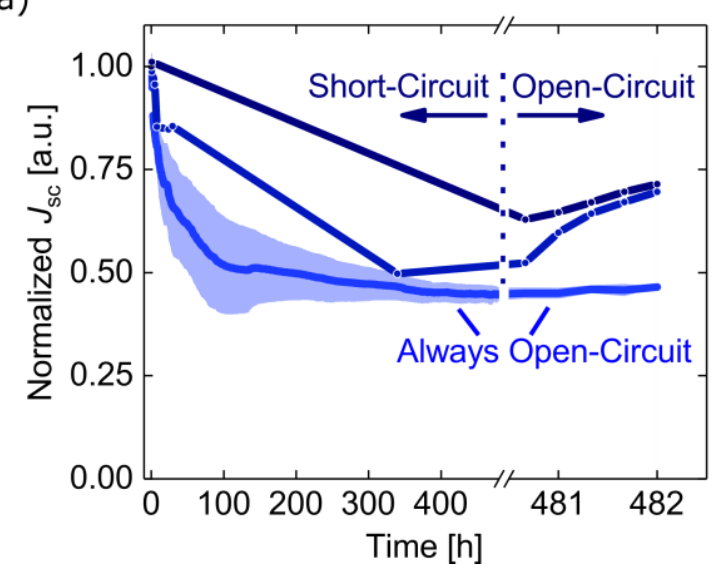

b)

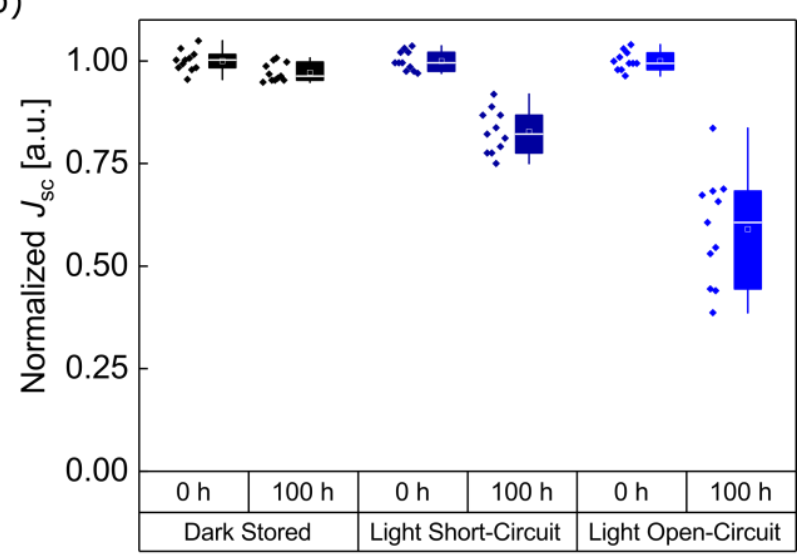

Figure 7 - Comparison between of the evolution of $J_{\mathrm{sc}}$ of devices that are at short-circuit and open-circuit conditions under light-soaking: a) Devices held at short-circuit present a reduced short current density loss once at open-circuit even after more than $\mathbf{4 0 0}$ hours of light-soaking; b) comparison of the shortcircuit current density of devices of that were light-soaked at open-circuit or short-circuit for 100 hours, or left in the dark for the same time.

Based on all our experiments, we suggest two explanations for the $J_{\mathrm{sc}}$ reduction. For this purpose, we highlight major conclusions of this work and key characteristics of this degradation. The $J_{\mathrm{sc}}$ reduction: 1) only happens in devices with $\mathrm{tBP}$ and $\mathrm{Au} ; 2$ ) is lightinduced and increases with forward bias, i.e., reduction of the internal field; 3) is caused by increased recombination. Two mechanisms that can explain these observations are:

i. Light Degrades tBP and the Degraded Species are Positively Charged. Positively charged tBP-related species are formed at the spiro-MeOTAD/Au interface during light-soaking (point 1 and 2). By biasing the device towards open-circuit under lightsoaking, the internal field of the device is reduced. Therefore, the positively charged tBP-related species can diffuse into the $\mathrm{CH}_{3} \mathrm{NH}_{3} \mathrm{PbI}_{3}$ (point 2). These charged tBPrelated species cause an increase of charge recombination (point 3).

ii. Light and the Internal Field of the Device Determine the $\mathrm{tBP}-\mathrm{CH}_{3} \mathrm{NH}_{3} \mathrm{PbI}_{3}$ Interaction. The Au retains the tBP in the spiro-MeOTAD (point 1). The low internal field at open-circuit under light-soaking leads to a larger concentration of $\mathrm{Pb}^{+}$(a rather immobile ion) and $\mathrm{I}^{-}$(a very mobile ion) ${ }^{[37,38]}$ at the $\mathrm{CH}_{3} \mathrm{NH}_{3} \mathrm{PbI}_{3} /$ spiro-MeOTAD interface than at short-circuit. Then, light facilitates the complexation of these ions with $\mathrm{tBP},{ }^{[32]}$ thereby creating defects (point 2). These defects increase charge recombination (point 3). 
It is impossible to distinguish between the two mechanisms with the current data, but work is under way to determine the exact mechanism. The key ideas of the mechanisms are summarized in Figure 8.

Applied Bias

Mechanism i)

Mechanism ii)
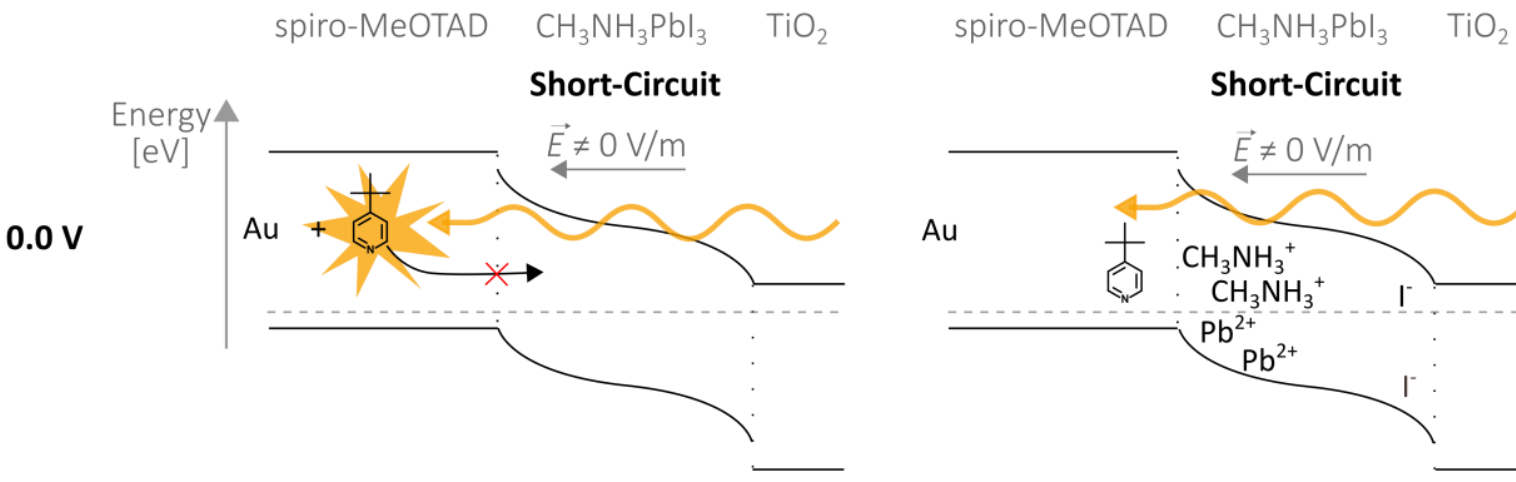
Short-Circuit
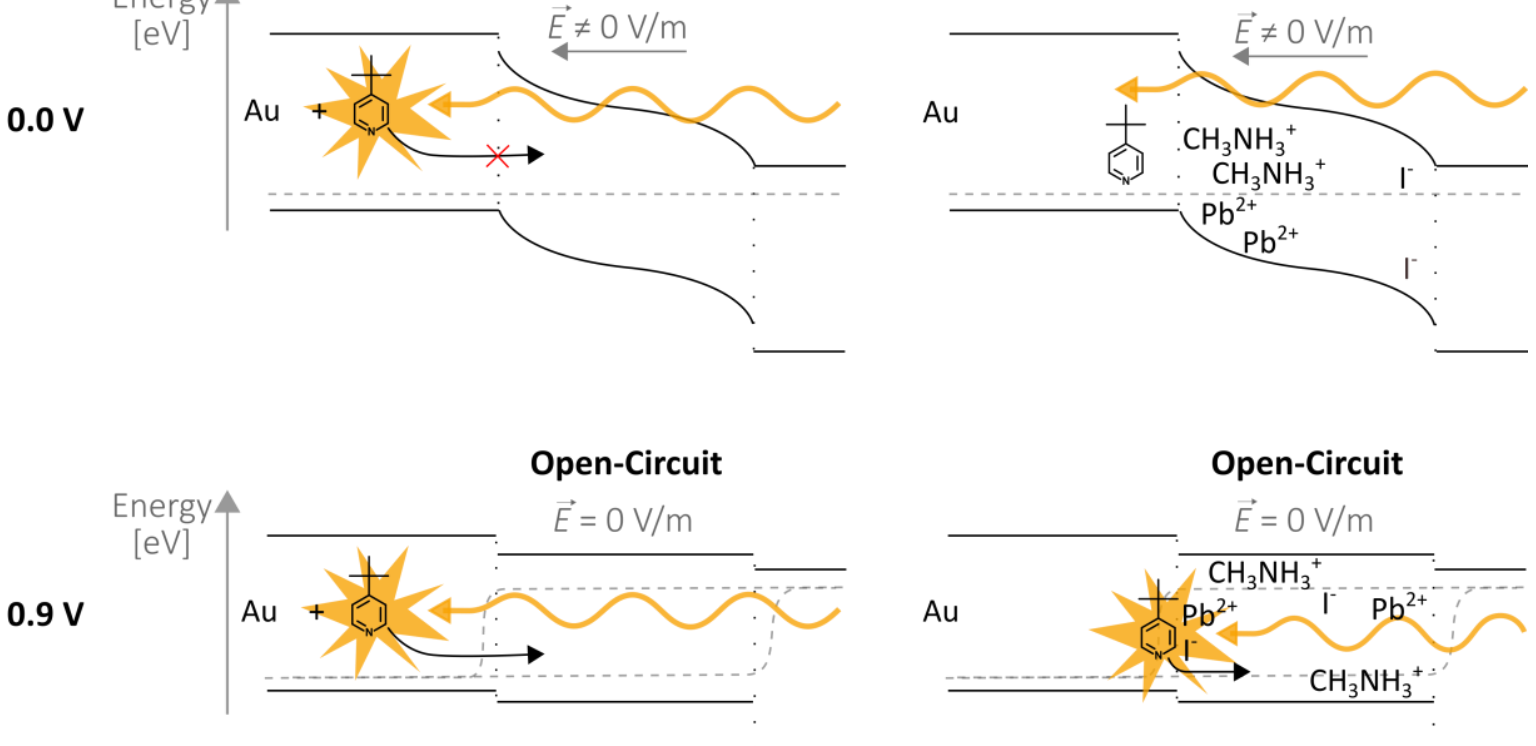

Figure 8 - Schematic band diagram illustrating the proposed degradation mechanisms. i) Light degrades tBP and the fragment are positively charged, so degradation is more severe at forward bias than at shortcircuit; ii) The concentration of $\mathrm{Pb}^{+}$and $\mathrm{I}^{+}$is higher at the $\mathrm{CH}_{3} \mathrm{NH}_{3} \mathrm{PbI} / 3$ spiro-MeOTAD interface at opencircuit than at short-circuit, leading to the formation of more defects.

The mechanisms proposed can also explain previous reports of light induced degradation. One work attributed light-induced degradation to forward bias, which is in line with our observations. ${ }^{[16]}$ However, we demonstrate that degradation also requires lightsoaking. The proposed mechanisms might also explain some of the degradation previously attributed to $\mathrm{Au}$ diffusion alone. ${ }^{[20]}$ Although we do not measure any $\mathrm{Au}$ in dark stored or light-soaked devices, we observe similar degradation curves.

\section{Conclusion}

In this work, we describe a new material related degradation mechanism for forward biased, light-soaked perovskite solar cells. We show that the degradation is caused by a species from spiro-MeOTAD during light-soaking of the device. This degradation requires the presence of tBP and $\mathrm{Au}$, but impacts the $\mathrm{CH}_{3} \mathrm{NH}_{3} \mathrm{PbI}_{3}$ layer. The effect of this degradation is enhanced by a reduction of the internal field of the device during light-soaking and causes an increase of non-radiative recombination. This finding has major implication for the field 
because: 1) devices need to be operated at forward bias to generate power under illumination; 2) many devices rely on spiro-MeOTAD and Au for high efficiency. The species responsible for degradation is part of the composition of typical spiro-MeOTAD layers, which means that this degradation mechanism will also be active in many high performing devices that use spiro-MeOTAD. Recently, significant increases in the light-stability for n-i-p devices were obtained by replacing spiro-MeOTAD and $\mathrm{Au}$, in agreement with the conclusions of this work. $^{[7,15]}$ Thus, this work stresses the need for the development of devices without spiroMeOTAD and Au to produce stable and high performing perovskite solar cells.

\section{Experimental Section}

Device Fabrication: The glass substrates with patterned ITO electrodes were purchased from Colorado Concept Coatings. The ITO coated glass was cleaned with ultrasonic baths of detergent, deionized water, acetone, and iso-propanol each for 10 minutes, and then transferred into an Angstrom Engineering evaporation system, equipped with an electron beam source. The $\mathrm{TiO}_{2}$ pellets purchased from Prof. Feierabend $\mathrm{GmbH}$ were reactive electron beam evaporated at a rate of $1 \AA$ /s onto ITO substrates, using a partial $\mathrm{O}_{2}$ pressure of $1.7 \times 10^{-4}$ Torr during the deposition, to maintain the stoichiometry of the film. To make the perovskite precursor solution, $\mathrm{PbCl}_{2}$ (purchased from Sigma-Aldrich) was mixed with and $\mathrm{CH}_{3} \mathrm{NH}_{3} \mathrm{I}$ (purchased from Lumtec) with a molar ratio of 1:3 in $\mathrm{N}, \mathrm{N}$-dimethylformamid (DMF). The precursor solution was stirred at room temperature for 10 minutes, and then spin coated at $3000 \mathrm{rpm}$ for $60 \mathrm{~s}$ onto the $\mathrm{TiO}_{2}$ layer. The obtained films were annealed on a hot plate at $90{ }^{\circ} \mathrm{C}$ in nitrogen for 1 hour to form a perovskite crystal structure. After that, $80 \mathrm{mg} / \mathrm{ml}$ spiro-OMeTAD solution doped with $17.5 \mu \mathrm{l}$ of lithium bis(trifluoromethanesulfonyl) imide $(520 \mathrm{mg} / \mathrm{ml}$ in acetonitrile) and $28.5 \mu \mathrm{l}$ of 4-tertbutylpyridine was spin-coated onto the perovskite films. All of the spin-coating processes mentioned above were performed in an $\mathrm{N}_{2}$ filled glove box. The perovskite films coated with spiro-OMeTAD were then exposed to air overnight for oxygen doping. The devices were completed by depositing the electrodes onto the spiro-OMeTAD through shadow masks, defining an active area of $0.13 \mathrm{~cm}^{2}$. The $100 \mathrm{~nm}$ of $\mathrm{Au}$ were evaporated in an Angstrom Engineering evaporation system at a base pressure of $10^{-4} \mathrm{~Pa}$ and evaporation rate of $1 \mathrm{~A} / \mathrm{s}$.

Device Characterization and Ageing: The initial and final photovoltaic characteristics were measured with a Keithley 2602A in four-wire configuration under an Abet xenon arc lamp with $100 \mathrm{~mW} \mathrm{~cm}^{-2}$ intensity and AM1.5G spectrum. The intensity of the lamps intensity was calibrated with an ISE Fraunhofer certified Si photodiode. The devices were measured 
from forward to reverse bias with a scan speed of $1 \mathrm{~V} \mathrm{~s}^{-1}$. After the initial characterization, the samples were continuously illuminated by a metal halide lamp with AM1.5G spectrum (containing UV light) and 1 sun intensity. The samples were tracked by a maximum power poin tracker, with a perturb and observe algorithm that adjusted the maximum power voltage every $30 \mathrm{~s}$, shorted, or left at open-circuit conditions between measurements every $20 \mathrm{~min}$. For the devices shorted or left at open-circuit conditions, the current-voltage characteristics of the device were measured with a Keithley 2400 with a scan speed of $0.5 \mathrm{~V} \mathrm{~s}^{-1}$. To hold the devices at maximum power point a in house device was used. The temperature of the samples during the illumination was $45^{\circ} \mathrm{C}$ as measured at the backside of the substrate. The transmission and reflectance were measured with a photospectrometer setup (Bentham PVE300) by illuminating the solar cell with a modulated monochromatic light (Xe and quartz halogen lamps). The spectral resolution was $5 \mathrm{~nm}$. X-ray diffraction (XRD) pattern was recorded on a PANalytical X'Pert Pro Materials Research Diffractometer using $\mathrm{Cu} \mathrm{K} \alpha$ radiation. For the photoluminescence (PL) measurements, the top Au contact was removed with Scotch tape, and chlorobenzene was spincoated on the layer stack to remove remnants of spiro-MeOTAD and of the top contact, prior to the measurements. The PL measurements were performed using a Hamamatsu Near Infrared Compact Fluorescence Lifetime Spectrometer C12132. The wavelength of the incident light radiation was $532 \mathrm{~nm}$. For the Time-of-Flight Secondary Ion Mass Spectroscopy (ToF-SIMS) measurements, the top $\mathrm{Au}$ contact was removed with Scotch tape prior to the measurements. This step is performed because: 1) Au sputtering requires a higher beam energy than the other layers, which would reduce depth resolution, 2) the high energy beam required to probe Au can also push this element further inside the device layers, creating an inaccurate compositional profile of $\mathrm{Au}$. ToF-SIMS analysis was conducted using a TOFSIMS V spectrometer (ION-TOF GmbH, Münster, Germany) equipped with a $30 \mathrm{keV}$ liquid metal ion gun (LMIG) operating with bismuth primary ions as analysis beam and Ar GCIB as sputter gun. Depth profiles were acquired using Ar GCIB of $2.5 \mathrm{eV} /$ atoms on a square area of 450 x $450 \mu \mathrm{m}^{2}$. Spectra were acquired in static mode (primary ion fluence $<10^{12}$ ions $\cdot \mathrm{cm}^{-2}$ ), in order to preserve the molecular information, using $\mathrm{Bi}^{3+}$ on a square area of $150 \times 150 \mu \mathrm{m}^{2}$. During analysis, charging of the surface was prevented by applying charge compensation using low-energy electron flood gun. Spectral interpretation was carried out using Surface Lab software v6.7 (ION-TOF GmbH, Münster, Germany). Principal Component Analysis (PCA) was performed on reconstructed profiles from the spiro-MeOTAD/perovskite interface using the $\begin{array}{lllll}\text { NESAC/BIO } & \text { MVA } & \text { Toolbox } & \text { (Spectragui } & \text { v2.7 }\end{array}$ 
https://www.nb.engr.washington.edu/mvsa/nbtoolbox). Prior to PCA analysis, the mass spectra were first normalized to the sum of selected peaks and then SQRT-mean-centered.

\section{Supporting Information}

Supporting Information is available from the Wiley Online Library or from the author.

\section{Acknowledgements}

The authors would also like to gratefully acknowledge Solliance for the financial support, the Initiating and Networking funding of the Helmholtz Association (HYIG of U. Paetzold). This research has received (partial) funding from the Flemish Government-Department of Economics, Science and Innovation. The authors also thank M. Jaysankar, T. Merckx, G. Uytterhoeven, A. Hadipour and. L. Rakocevic, W. Song for the fruitful discussions. The authors would like to acknowledge Dr. D. Graham (NESLAB, University of Washington, USA) for providing the MVA toolbox used for the PCA data analysis.

Received: ((will be filled in by the editorial staff))

Revised: ((will be filled in by the editorial staff)) Published online: ((will be filled in by the editorial staff))

\section{References}

[1] NREL, can be found under https://www.nrel.gov/pv/assets/images/efficiencychart.png, 2017.

[2] M. Saliba, T. Matsui, J.-Y. Seo, K. Domanski, J.-P. Correa-Baena, M. K. Nazeeruddin, S. M. Zakeeruddin, W. Tress, A. Abate, A. Hagfeldt, M. Grätzel, Energy Environ. Sci. 2016, 9, 1989.

[3] M. Saliba, T. Matsui, K. Domanski, J.-Y. Seo, A. Ummadisingu, S. M. Zakeeruddin, J.-P. Correa-Baena, W. R. Tress, A. Abate, A. Hagfeldt, M. Gratzel, Science (80-. ). 2016, $354,206$.

[4] D. Bi, W. Tress, M. I. Dar, P. Gao, J. Luo, C. Renevier, K. Schenk, A. Abate, F. Giordano, J.-P. Correa Baena, J.-D. Decoppet, S. M. Zakeeruddin, M. K. Nazeeruddin, M. Gratzel, A. Hagfeldt, Sci. Adv. 2016, 2, e1501170.

[5] D.-Y. Son, J.-W. Lee, Y. J. Choi, I.-H. Jang, S. Lee, P. J. Yoo, H. Shin, N. Ahn, M.

Choi, D. Kim, N.-G. Park, Nat. Energy 2016, 1, 16081. 
[6] X. Li, D. Bi, C. Yi, J.-D. Decoppet, J. Luo, S. M. Zakeeruddin, A. Hagfeldt, M. Gratzel, Science (80-. ). 2016, 353, 58.

[7] Y. Hou, X. Du, S. Scheiner, D. P. McMeekin, Z. Wang, N. Li, M. S. Killian, H. Chen, M. Richter, I. Levchuk, N. Schrenker, E. Spiecker, T. Stubhan, N. A. Luechinger, A. Hirsch, P. Schmuki, H.-P. Steinrück, R. H. Fink, M. Halik, H. J. Snaith, C. J. Brabec, Science (80-. ). 2017, 358, 1192.

[8] M. Bag, L. A. Renna, R. Y. Adhikari, S. Karak, F. Liu, P. M. Lahti, T. P. Russell, M. T. Tuominen, D. Venkataraman, J. Am. Chem. Soc. 2015, 137, 13130.

[9] A. J. Neukirch, W. Nie, J.-C. Blancon, K. Appavoo, H. Tsai, M. Y. Sfeir, C. Katan, L. Pedesseau, J. Even, J. J. Crochet, G. Gupta, A. D. Mohite, S. Tretiak, Nano Lett. 2016, 16, 3809.

[10] W. Nie, J. Blancon, A. J. Neukirch, K. Appavoo, H. Tsai, M. Chhowalla, M. A. Alam, M. Y. Sfeir, C. Katan, J. Even, S. Tretiak, J. J. Crochet, G. Gupta, A. D. Mohite, Nat. Commun. 2016, 7, 11574.

[11] I. Hwang, K. Yong, ACS Appl. Mater. Interfaces 2016, 8, 4226.

[12] A. M. Soufiani, Z. Hameiri, S. Meyer, S. Lim, M. J. Y. Tayebjee, J. S. Yun, A. HoBaillie, G. J. Conibeer, L. Spiccia, M. A. Green, Adv. Energy Mater. 2017, 7, 1602111.

[13] K. Wojciechowski, T. Leijtens, S. Siprova, C. Schlueter, M. T. Hörantner, J. T.-W. Wang, C.-Z. Li, A. K.-Y. Jen, T.-L. Lee, H. J. Snaith, J. Phys. Chem. Lett. 2015, 6, 2399.

[14] L. Qiu, L. K. Ono, Y. Jiang, M. R. Leyden, S. R. Raga, S. Wang, Y. Qi, J. Phys. Chem. $B$ 2018, 122, 511.

[15] J. A. Christians, P. Schulz, J. S. Tinkham, T. H. Schloemer, S. P. Harvey, B. J. Tremolet de Villers, A. Sellinger, J. J. Berry, J. M. Luther, Nat. Energy 2018, 3, 68.

[16] S. Bae, S. Kim, S.-W. Lee, K. J. Cho, S. Park, S. Lee, Y. Kang, H. Lee, D. Kim, J. Phys. Chem. Lett. 2016, 7, 3091.

[17] K. Domanski, B. Roose, T. Matsui, M. Saliba, S.-H. Turren-Cruz, J.-P. Correa-Baena, 
C. R. Carmona, G. Richardson, J. M. Foster, F. De Angelis, J. M. Ball, A. Petrozza, N. Mine, M. K. Nazeeruddin, W. Tress, M. Grätzel, U. Steiner, A. Hagfeldt, A. Abate, Energy Environ. Sci. 2017, 10, 604 .

[18] S. Cacovich, L. Ciná, F. Matteocci, G. Divitini, P. A. Midgley, A. Di Carlo, C. Ducati, Nanoscale 2017, 9, 4700.

[19] C. Li, A. Guerrero, Y. Zhong, A. Gräser, C. A. M. Luna, J. Köhler, J. Bisquert, R. Hildner, S. Huettner, Small 2017, 13, 1701711.

[20] K. Domanski, J.-P. Correa-Baena, N. Mine, M. K. Nazeeruddin, A. Abate, M. Saliba, W. Tress, A. Hagfeldt, M. Grätzel, ACS Nano 2016, 10, 6306.

[21] K. Domanski, E. A. Alharbi, A. Hagfeldt, M. Grätzel, W. Tress, Nat. Energy 2018, 3, 61.

[22] Z. Li, C. Xiao, Y. Yang, S. P. Harvey, D. H. Kim, J. A. Christians, M. Yang, P. Schulz, S. U. Nanayakkara, C.-S. Jiang, J. M. Luther, J. J. Berry, M. C. Beard, M. M. Al-Jassim, K. Zhu, Energy Environ. Sci. 2017, 10, 1234.

[23] M. O. Reese, S. A. Gevorgyan, M. Jørgensen, E. Bundgaard, S. R. Kurtz, D. S. Ginley, D. C. Olson, M. T. Lloyd, P. Morvillo, E. A. Katz, A. Elschner, O. Haillant, T. R. Currier, V. Shrotriya, M. Hermenau, M. Riede, K. R. Kirov, G. Trimmel, T. Rath, O. Inganäs, F. Zhang, M. Andersson, K. Tvingstedt, M. Lira-Cantu, D. Laird, C. McGuiness, S. (Jimmy) Gowrisanker, M. Pannone, M. Xiao, J. Hauch, R. Steim, D. M. DeLongchamp, R. Rösch, H. Hoppe, N. Espinosa, A. Urbina, G. Yaman-Uzunoglu, J.-B. Bonekamp, A. J. J. M. van Breemen, C. Girotto, E. Voroshazi, F. C. Krebs, Sol. Energy Mater. Sol. Cells 2011, 95, 1253. [24] T. Malinauskas, D. Tomkute-Luksiene, R. Sens, M. Daskeviciene, R. Send, H. Wonneberger, V. Jankauskas, I. Bruder, V. Getautis, ACS Appl. Mater. Interfaces 2015, 7, 11107.

[25] F. Matteocci, L. Cinà, E. Lamanna, S. Cacovich, G. Divitini, P. A. Midgley, C. Ducati, A. Di Carlo, Nano Energy 2016, 30, 162. 
[26] D. J. Graham, M. S. Wagner, D. G. Castner, Appl. Surf. Sci. 2006, 252, 6860.

[27] Y. Yokoyama, T. Kawashima, M. Ohkawa, H. Iwai, S. Aoyagi, Surf. Interface Anal. $\mathbf{2 0 1 5}, 47,439$.

[28] J. H. Heo, H. J. Han, D. Kim, T. K. Ahn, S. H. Im, Energy Environ. Sci. 2015, 8, 1602.

[29] J. Liu, Y. Wu, C. Qin, X. Yang, T. Yasuda, A. Islam, K. Zhang, W. Peng, W. Chen, L. Han, Energy Environ. Sci. 2014, 7, 2963.

[30] W. Li, H. Dong, L. Wang, N. Li, X. Guo, J. Li, Y. Qiu, J. Mater. Chem. A 2014, 2 , 13587.

[31] K. Aitola, K. Domanski, J.-P. Correa-Baena, K. Sveinbjörnsson, M. Saliba, A. Abate, M. Grätzel, E. Kauppinen, E. M. J. Johansson, W. Tress, A. Hagfeldt, G. Boschloo, Adv. Mater. 2017, 29, 1606398.

[32] D. Mollenhauer, N. Gaston, E. Voloshina, B. Paulus, J. Phys. Chem. C 2013, 117, 4470.

[33] L. Stolberg, J. Lipkowski, D. E. Irish, J. Electroanal. Chem. Interfacial Electrochem. 1990, 296, 171.

[34] E. L. Unger, E. T. Hoke, C. D. Bailie, W. H. Nguyen, A. R. Bowring, T. Heumüller, M. G. Christoforo, M. D. McGehee, Energy Environ. Sci. 2014, 7, 3690.

[35] C. Eames, J. M. Frost, P. R. F. Barnes, B. C. O’Regan, A. Walsh, M. S. Islam, Nat. Commun. 2015, 6, 2. 